\title{
Streptomyces atacamensis sp. nov., isolated from an extreme hyper-arid soil of the Atacama Desert, Chile
}

Correspondence

M. Goodfellow

m.goodfellow@ncl.ac.uk

\author{
Rakesh Santhanam, ${ }^{1}$ Chinyere K. Okoro, ${ }^{1}$ Xiaoying Rong, ${ }^{2}$ Ying Huang, ${ }^{2}$ \\ Alan T. Bull, ${ }^{1,3}$ Hang-Yeon Weon, ${ }^{4}$ Barbara A. Andrews, ${ }^{5}$ Juan A. Asenjo ${ }^{5}$ \\ and Michael Goodfellow ${ }^{1}$
}
${ }^{1}$ School of Biology, Newcastle University, Newcastle upon Tyne NE1 7RU, UK
${ }^{2}$ State Key Laboratory of Microbial Resources, Institute of Microbiology, Chinese Academy of Sciences, Beijing 100101, PR China
${ }^{3}$ Department of Biosciences, University of Kent, Canterbury CT2 7NJ, UK
${ }^{4}$ Korean Agricultural Culture Collection, Agricultural Microbiological Team, National Academy of Agricultural Science, Rural Development Administration, Suwon 441-707, Republic of Korea
${ }^{5}$ Department of Chemical Engineering and Biotechnology, University of Chile, Beauchef 850, Santiago, Chile

\begin{abstract}
The taxonomic position of a Streptomyces strain isolated from an extreme hyper-arid soil sample collected from the Atacama Desert was determined using a polyphasic approach. The strain, isolate $\mathrm{C} \mathrm{O}^{\top}$, had chemical and morphological features typical of members of the genus Streptomyces and formed a distinct phyletic line in the Streptomyces 16S rRNA gene tree, together with the type strain of Streptomyces radiopugnans. The two strains were distinguished readily using a combination of phenotypic properties and by a DNA-DNA relatedness value of $23.17( \pm 0.95) \%$. On the basis of these genotypic and phenotypic data, it is proposed that isolate $\mathrm{C}^{\top} 0^{\top}\left(=\mathrm{CGMCC} 4.7018^{\top}=\mathrm{KACC} 15492^{\top}\right.$ ) be classified in the genus Streptomyces as Streptomyces atacamensis sp. nov.
\end{abstract}

Streptomyces strains remain a rich source of commercially significant antibiotics (Goodfellow \& Fiedler, 2010). In the search for new therapeutic compounds it is important to screen novel isolates (Antony-Babu \& Goodfellow, 2008), such as those isolated recently from hyper-arid Atacama Desert soils, Chile (Bull, 2004; Okoro et al., 2009). We have shown that two Streptomyces strains from the hyper-arid salt flat Salar de Atacama produce new ansamycin and 22membered macrolactones that express a range of antibacterial and anti-tumour activities (Nachtigall et al., 2011; Rateb et al., 2011a, 2011b). A second remarkable feature of the genus Streptomyces is the huge number of species with validly published names, nearly 600 to date (Euzéby, 2011). The subgeneric classification of the genus, while complex, has been clarified by the application of genotypic and phenotypic procedures (Labeda et al., 2012), which have also been used to delineate novel species which synthesize bioactive compounds (Kumar \& Goodfellow, 2008, 2010).

Abbreviation: ISP, International Streptomyces project.

The GenBank/EMBL/DDBJ accession number for the $16 \mathrm{~S}$ rRNA gene sequence of strain $\mathrm{C}^{\circ} \mathrm{O}^{\top}$ is HE577171.
The present study was designed to establish the taxonomic status of a Streptomyces strain, isolate $\mathrm{C} 60^{\mathrm{T}}$, recovered from an even more extreme hyper-arid region of the Atacama Desert. The sampling site in the Valle de la Luna $\left(23^{\circ} 02^{\prime} \mathrm{S}\right.$ $68^{\circ} 20^{\prime} \mathrm{W}$ ) is defined as extremely hyper-arid or absolute desert on the basis of the ratio of mean rainfall to mean evaporation (Houston, 2006; Okoro et al., 2009) and is devoid of vegetation. Nevertheless, small numbers [100-500 c.f.u. (g soil) ${ }^{-1}$ depending on the isolation medium used] of putative actinomycetes were recovered, among them isolate

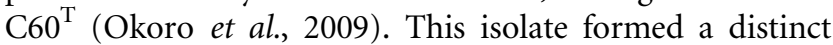
subclade in the 16S rRNA gene tree based on sequences from members of the genus Streptomyces and was shown to contain non-ribosomal peptide synthetase genes. A taxonomic study conducted using a polyphasic approach and based on a combination of genotypic and phenotypic methods, indicated that the isolate should be recognized as a novel species of the genus Streptomyces.

Strain $\mathrm{C} 60^{\mathrm{T}}$ was isolated on raffinose-histidine agar (Vickers et al., 1984), supplemented with cycloheximide $(25 \mu \mathrm{g}$ $\left.\mathrm{ml}^{-1}\right)$ and nystatin $\left(25 \mu \mathrm{g} \mathrm{ml}^{-1}\right)$, which had been inoculated with a soil suspension and incubated at $28{ }^{\circ} \mathrm{C}$ 


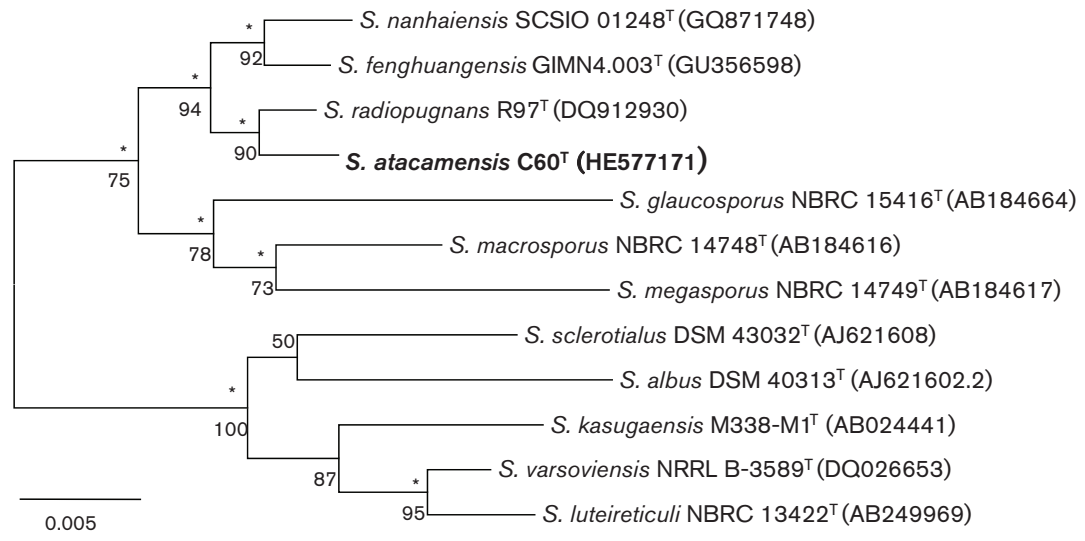

Fig. 1. Neighbour-joining tree based on nearly complete 16S rRNA gene sequences (1457 nt) showing relationships between isolate $\mathrm{C}^{\top} \mathrm{O}^{\top}$ and closely related species of the genus Streptomyces. Asterisks indicate branches of the tree that were also found using the maximum-parsimony and minimum-evolution tree-making algorithms. Numbers at the nodes are percentage bootstrap values based on 1000 resampled datasets: only values $\geqslant 50 \%$ are given. Bar, 0.005 substitutions per nucleotide position.

for 14 days. The isolate was maintained on modified Bennett's agar slopes (Jones, 1949) at $4{ }^{\circ} \mathrm{C}$ and as suspensions of spores and hyphae in $20 \%$, v/v, glycerol at $-20{ }^{\circ} \mathrm{C}$. Biomass for the molecular systematic and most of the chemotaxonomic studies was scraped from modified Bennett's agar plates, which had been incubated for 14 days at $28{ }^{\circ} \mathrm{C}$, and was washed twice in distilled water. Biomass for the chemotaxonomic studies was freeze-dried and that for the molecular systematic work stored at $-20{ }^{\circ} \mathrm{C}$. Biomass for the fatty acid analysis was harvested from glucose yeast extract-malt extract broth (Shirling \& Gottlieb, 1966) after 3 days at $25^{\circ} \mathrm{C}$.

Genomic DNA was extracted from isolate $\mathrm{C} 60^{\mathrm{T}}$ and amplified by PCR, and 16S rRNA gene sequencing was performed as previously described by Kim \& Goodfellow (2002). The resultant, almost complete sequence (1457 nt) was compared with the corresponding sequences of the most closely related type strains of members of the genus Streptomyces using the EzTaxon server 2 (Chun et al., 2007); gene sequences were aligned using CLUSTAL W (Thompson et al., 1994). Phylogenetic trees were generated using the maximumparsimony (Fitch, 1971), minimum-evolution (Rzhetsky \& Nei, 1992) and neighbour-joining (Saitou \& Nei, 1987) treemaking algorithms from MEGA4 (Tamura et al., 2007); the Jukes \& Cantor (1969) model was used to derive an evolutionary distance matrix for the neighbour-joining method. Tree topologies were evaluated by a bootstrap analysis (Felsenstein, 1985) of the neighbour-joining dataset based on 1000 replicates using MEGA4.0.

Comparison of the almost complete 16S rRNA gene sequence of isolate $\mathrm{C}^{\mathrm{T}} 0^{\mathrm{T}}$ with the corresponding sequences of the closely related type strains showed that it formed a branch in the Streptomyces gene tree with Streptomyces radiopugnans CGMCC $4.3519^{\mathrm{T}}$, a relationship which was supported by all of the tree-making algorithms and had a bootstrap value of $90 \%$ (Fig. 1). The 16S rRNA gene similarity between these organisms was $99.4 \%$, a value which corresponded to 9 nucleotide differences over 1457 locations. The novel strain formed a well supported subclade, together with a corresponding branch composed of the type strains of Streptomyces sanyensis and Streptomyces nanhaiensis (Fig. 1).
Isolate $\mathrm{C} 0^{\mathrm{T}}$ was examined for chemotaxonomic and morphological properties considered to be typical of the genus Streptomyces (Williams et al., 1989; Manfio et al., 1995). The arrangement of hyphae and spore chains of the organism grown for 14 days at $28{ }^{\circ} \mathrm{C}$ on oatmeal agar [International Streptomyces project (ISP) medium 3; Shirling \& Gottlieb, 1966] were determined using the coverslip technique of Kawato \& Shinobu (1959). Spore chain morphology and spore surface ornamentation were detected by examining gold-coated, dehydrated specimens taken from the 14-day oatmeal agar plates, using an electron microscope (Cambridge Stereoscan 240), following the procedure described by O'Donnell et al. (1993). The isomers of diaminopimelic acid were analysed using the procedure developed by Hasegawa et al. (1983) and menaquinones were extracted and purified according to Collins (1985) and then examined by HPLC (Minnikin et al., 1984). The cellular fatty acids were extracted, methylated and separated by GC (model 6890; Hewlett Packard), according to the protocol of the Sherlock Microbial Identification System (MIDI; Sasser, 1990). The fatty acid methyl esters were identified and quantified

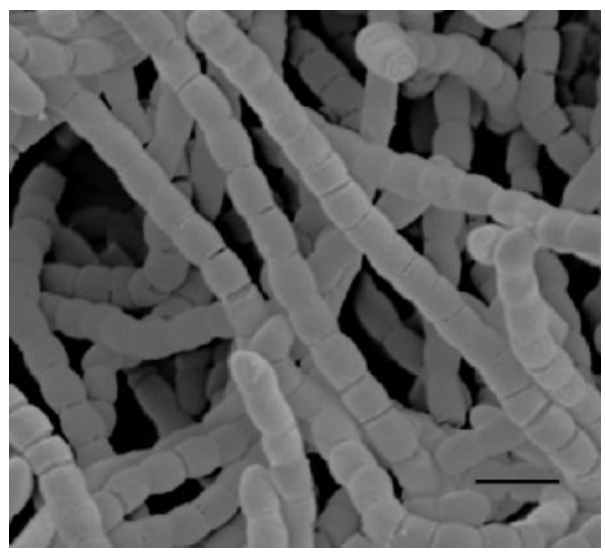

Fig. 2. Scanning electron micrograph of isolate $\mathrm{C} 60^{\top}$ on oatmeal agar after 14 days at $28{ }^{\circ} \mathrm{C}$ showing straight chains of spores. Bar, $1 \mu \mathrm{m}$. 
Table 1. Growth and cultural characteristics of strain $\mathrm{C} 60^{\top}$ on standard ISP agar media, following incubation at $28{ }^{\circ} \mathrm{C}$ for 14 days +++ , Abundant growth; ++ , moderate growth. The isolate did not form diffusible pigments on any of the media tested.

\begin{tabular}{|lccc|}
\hline Medium & Growth & Substrate mycelium colour & Aerial mycelium colour \\
\hline Glycerol asparagine agar (ISP 5) & ++ & Light yellow & Light yellow \\
Inorganic salts starch agar (ISP 4) & +++ & Brownish white & White \\
Oatmeal agar (ISP 3) & +++ & Olive green & Grey \\
Peptone yeast extract iron agar & +++ & Creamy brown & White \\
(ISP 6) & & Cream & White \\
Tryptone yeast extract agar (ISP 1) & ++ & Cream & White \\
Tyrosine agar (ISP 7) & ++ & White & Grey \\
Glucose yeast extract-malt extract & +++ & & \\
agar (ISP 2) & & & \\
\hline
\end{tabular}

by using the ACTIN1 database (version 6.10) of the Sherlock Microbial Identification System.

The isolate formed an extensively branched substrate mycelium and abundant grey aerial hyphae on oatmeal agar. At maturity, aerial hyphae differentiated into long, straight chains of cylindrical, smooth-surfaced spores (Fig. 2). The organism contained LL-diaminopimelic acid in wholeorganism hydrolysates and hexa- and octa-hydrogenated menaquinones with nine isoprene units $\left[\mathrm{MK}-9\left(\mathrm{H}_{6}, \mathrm{H}_{8}\right)\right]$ in the

Table 2. Phenotypic properties that distinguish isolate $\mathrm{C} 60^{\top}$ from the type strain of Streptomyces radiopugnans

All of the data were from the present study, unless indicated otherwise. +, Positive; - , negative.

\begin{tabular}{|c|c|c|}
\hline Characteristic & $\mathrm{C} 60^{\mathrm{T}}$ & S. radiopugnans CGMCC $4.3519^{\mathrm{T}}$ \\
\hline $\begin{array}{l}\text { Aerial spore mass colour on oatmeal and glucose } \\
\text { yeast extract-malt extract agar media }\end{array}$ & Grey & Pale grey ${ }^{\star}$ \\
\hline Spore chain morphology & Straight & Spiral $^{*}$ \\
\hline Spore surface ornamentation & Smooth & Rough to warty ${ }^{\star}$ \\
\hline \multicolumn{3}{|l|}{ Biochemical tests } \\
\hline Arbutin hydrolysis & - & + \\
\hline Urease production & + & - \\
\hline \multicolumn{3}{|l|}{ Degradation tests } \\
\hline Cellulose & - & + \\
\hline Elastin & + & - \\
\hline Guanine & - & + \\
\hline Keratin & + & - \\
\hline Tween 40 & + & - \\
\hline Xanthine & - & + \\
\hline \multicolumn{3}{|l|}{ Growth on sole carbon sources $(1 \%, \mathrm{w} / \mathrm{v})$} \\
\hline Dextran & + & - \\
\hline D-Galactose & + & - \\
\hline Inulin & - & + \\
\hline Lactose & + & - \\
\hline meso-Inositol & + & - \\
\hline D-Raffinose & + & - \\
\hline D-Sucrose & - & + \\
\hline D-Trehalose & + & - \\
\hline Sodium azide $(0.1 \%, \mathrm{w} / \mathrm{v})$ & - & + \\
\hline Sodium propionate $(0.1 \%, \mathrm{w} / \mathrm{v})$ & + & - \\
\hline \multicolumn{3}{|l|}{ Growth on sole nitrogen sources $(0.1 \%, \mathrm{w} / \mathrm{v})$} \\
\hline L-Phenylalanine & + & - \\
\hline L-Threonine & + & - \\
\hline L-Valine & + & - \\
\hline Growth in presence of $7 \%, w / v, ~ N a C l$ & + & - \\
\hline
\end{tabular}

${ }^{*}$ Data taken from Mao et al. (2007). 
ratio $5: 1$. The fatty acid profile contained major amounts of iso- $\mathrm{C}_{15: 0}(11.6 \%)$, anteiso- $\mathrm{C}_{15: 0}(12.4 \%)$, iso- $\mathrm{C}_{16: 0}(13.5 \%)$, iso- $\mathrm{C}_{17: 0}(6.2 \%)$ and anteiso- $\mathrm{C}_{17: 0}(13.7 \%)$. All of these properties are in line with the classification of the isolate in the genus Streptomyces (Williams et al., 1989; Manfio et al., 1995).

DNA-DNA relatedness studies were performed, in triplicate, between strain $\mathrm{C}^{\mathrm{T}}{ }^{\mathrm{T}}$ and $S$. radiopugnans CGMCC $4.3519^{\mathrm{T}}$ using the microplate method and biotinylated probe DNA (Ezaki et al., 1989) with modifications as described by Rong \& Huang (2010). The two strains shared a mean DNA-DNA relatedness similarity of $23.17( \pm 0.95) \%$, far removed from the $70 \%$ cut-off point recommended for the delineation of genomic species (Wayne et al., 1987). The isolate had a DNA G + C content of $71.5 \mathrm{~mol} \%$.

Isolate $\mathrm{C}^{\mathrm{T}}{ }^{\mathrm{T}}$ and $\mathrm{S}$. radiopugnans CGMCC $4.3519^{\mathrm{T}}$ were examined for a broad range of phenotypic properties as described by Williams et al. (1983); the isolate was also subjected to additional tests drawn from those used by Williams and his colleagues. In addition, cultural characteristics of the isolate were recorded after incubation at $28{ }^{\circ} \mathrm{C}$ for 14 days on standard media used in the ISP (Shirling \& Gottlieb, 1966). The strain grew well on all of the ISP media, showing a range of aerial spore mass and substrate mycelial pigments (Table 1).

Isolate $\mathrm{C} 60^{\mathrm{T}}$ and $S$. radiopugnans CGMCC $4.3519^{\mathrm{T}}$ could be distinguished readily on the basis of a broad range of phenotypic properties as shown in Table 2. Unlike the latter strain, isolate $\mathrm{C} 60^{\mathrm{T}}$ formed straight chains of smooth-surfaced spores, degraded elastin, keratin and Tween 40, hydrolysed urea and showed a greater propensity to grow on sole carbon and sole nitrogen sources. In contrast, both strains hydrolysed aesculin, produced hydrogen sulphide; degraded hypoxanthine, but not tributryin, uric acid or xylan; grew on L-arabinose, D-mannitol, xylitol and D-xylose as sole carbon sources, grew at $10-35{ }^{\circ} \mathrm{C}$ and from $\mathrm{pH} 4$ to 11. The results of the additional phenotypic tests mentioned above are given in the species description.

It is suggested that minimal standards for the delineation of members of the genus Streptomyces should be based on an appropriate selection of genotypic and phenotypic properties (Manfio et al., 1995; Kumar \& Goodfellow, 2008, 2010). In the present study, isolate $\mathrm{C} 60^{\mathrm{T}}$ was distinguished readily from the type strain of $S$. radiopugnans, its nearest phylogenetic neighbour, on the basis of 16S rRNA gene sequence similarity, DNA-DNA hybridization and phenotypic data. It is, therefore, proposed that isolate $\mathrm{C} 60^{\mathrm{T}}$ be recognized as a novel species, Streptomyces atacamensis sp. nov.

\section{Description of Streptomyces atacamensis sp. nov.}

Streptomyces atacamensis (a.ta.cam.en'sis. N.L. masc. adj. atacamensis belonging to an extreme hyper-arid site in the Atacama Desert of north-west Chile, the source of the soil from which the strain was isolated).

Aerobic, Gram-positive, non-acid-alcohol-fast actinomycete, which forms an extensively branched substrate mycelium that carries aerial hyphae that differentiate into straight chains of smooth-surfaced, cyclindrical spores (0.7$0.9 \mu \mathrm{m}$ ) on oatmeal agar. Does not form melanin on peptone yeast extract iron or tyrosine agars. Grows at 10 to $45{ }^{\circ} \mathrm{C}$ and from $\mathrm{pH} 4$ to 11 . Degrades adenine, casein, chitin, gelatin, L-tyrosine and Tween 40 , but not DNA or RNA. Amygdalin, D-arabitol, D-fructose, D-glucose, glycerol, glycogen, maltose, D-mannose, meso-erythritol, D-salicin, Dsorbitol and L-sorbose are used as sole carbon sources, but not L-arabitol, dulcitol or melezitose (all at $1 \%$, w/v). Similarly, uses butane-1,4-diol and propanol, but not methanol as sole carbon sources (at $1 \%, v / v)$. Sodium citrate, sodium malonate and sodium pyruvate, but not sodium acetate, are used as sole carbon sources (at $0.1 \%, \mathrm{w} /$ v). L-Alanine, L-aminobutyric acid, glycine, L-histidine, Lisoleucine, DL-methionine, DL-norleucine, L-norvaline, Lornithine, L-proline, L-serine and L-tryptophan are used as sole nitrogen sources. Additional phenotypic features are mentioned in the text and in Tables 1 and 2 . Chemotaxonomic properties are typical of the genus Streptomyces.

The type and only strain, $660^{\mathrm{T}}$ (=CGMCC $4.7018^{\mathrm{T}}=$ KACC $15492^{\mathrm{T}}$ ), was isolated from the Valle de la Luna region of the Atacama Desert, north-west Chile. The species description is based on a single strain and hence serves as the description of the type strain. The DNA G $+\mathrm{C}$ content of the type strain is $71.5 \mathrm{~mol} \%$.

\section{Acknowledgements}

A. T. B. thanks the Leverhulme Trust for an Emeritus Fellowship, and A. T. B. and J.A.S. thank the Royal Society for their International Joint Project grant JP100654; the work was also funded in part by the National Science Foundation of China (grant 31100003).

\section{References}

Antony-Babu, S. \& Goodfellow, M. (2008). Biosystematics of alkaliphilic streptomycetes isolated from seven locations across a beach and dune sand system. Antonie van Leeuwenhoek 94, 581-591.

Bull, A. T. (editor) (2004). Microbial Diversity and Bioprospecting. Washington, DC: American Society for Microbiology.

Chun, J., Lee, J. H., Jung, Y., Kim, M., Kim, S., Kim, B. K. \& Lim, Y. W. (2007). EzTaxon: a web-based tool for the identification of prokaryotes based on $16 \mathrm{~S}$ ribosomal RNA gene sequences. Int J Syst Evol Microbiol 57, 2259-2261.

Collins, M. D. (1985). Isoprenoid quinone analysis in bacterial classification and identification. In Chemical Methods in Bacterial Systematics, pp. 267-287. Edited by M. Goodfellow \& D. E. Minnikin. London: Academic Press.

Euzéby, J. P. (2011). List of bacterial names with standing in nomenclature: a folder available on the Internet. [Last full update 9 September 2011]. http://www.bacterio.cict.fr

Ezaki, T., Hashimoto, Y. \& Yabuuchi, E. (1989). Fluorometric deoxyribonucleic acid-deoxyribonucleic acid hybridization in microdilution wells as an alternative to membrane filter hybridization in which radioisotopes are used to determine genetic relatedness among bacterial strains. Int J Syst Bacteriol 39, 224-229. 
Felsenstein, J. (1985). Confidence limits on phylogenies: an approach using the bootstrap. Evolution 39, 783-791.

Fitch, W. M. (1971). Toward defining the course of evolution: minimum change for a specific tree topology. Syst Zool 20, 406-416.

Goodfellow, M. \& Fiedler, H.-P. (2010). A guide to successful bioprospecting: informed by actinobacterial systematics. Antonie van Leeuwenhoek 98, 119-142.

Hasegawa, T., Takizawa, M. \& Tanida, S. (1983). A rapid analysis for chemical grouping of aerobic actinomycetes. J Gen Appl Microbiol 29, 319-322.

Houston, J. (2006). Evaporation in the Atacama Desert: an empirical study of spatio-temporal variations and their causes. J Hydrol (Amst) 330, 402-412.

Jones, K. L. (1949). Fresh isolates of actinomycetes in which the presence of sporogenous aerial mycelia is a fluctuating characteristic. J Bacteriol 57, 141-145.

Jukes, T. H. \& Cantor, C. R. (1969). Evolution of protein molecules. In Mammalian Protein Metabolism, pp. 21-132. Edited by H. N. Munro. London: Academic Press.

Kawato, M. \& Shinobu, R. (1959). On Streptomyces herbaricolor sp. nov., supplement: a single technique for microscopical observation. Mem Osaka Unit Lib Arts Educ B Nat Sci 8, 114-119.

Kim, S. B. \& Goodfellow, M. (2002). Streptomyces thermospinisporus sp. nov., a moderately thermophilic carboxydotrophic streptomycete isolated from soil. Int J Syst Evol Microbiol 52, 1225-1228.

Kumar, Y. \& Goodfellow, M. (2008). Five new members of the Streptomyces violaceusniger $16 \mathrm{~S}$ rRNA gene clade: Streptomyces castelarensis sp. nov., comb. nov., Streptomyces himastatinicus sp. nov., Streptomyces mordarskii sp. nov., Streptomyces rapamycinicus sp. nov. and Streptomyces ruanii sp. nov. Int J Syst Evol Microbiol 58, 1369-1378.

Kumar, Y. \& Goodfellow, M. (2010). Reclassification of Streptomyces hygroscopicus strains as Streptomyces aldersoniae sp. nov., Streptomyces angustmyceticus sp. nov., comb. nov., Streptomyces ascomycinicus sp. nov., Streptomyces decoyicus sp. nov., comb. nov., Streptomyces milbemycinicus sp. nov. and Streptomyces wellingtoniae sp. nov. Int J Syst Evol Microbiol 60, 769-775.

Labeda, D. P., Goodfellow, M., Brown, R., Ward, A. C., Lanoot, B., Vanncanneyt, M., Swings, J., Kim, S.-B., Liu, Z. \& other authors (2012). Phylogenetic study of the species within the family Streptomycetaceae. Antonie van Leeuwenhoek 101, 73-104.

Manfio, G. P., Zakrzewska-Czerwinska, J., Atalan, E. \& Goodfellow, M. (1995). Towards minimal standards for the description of Streptomyces species. Biotechnologia 7-8, 242-253.

Mao, J., Tang, Q., Zhang, Z., Wang, W., Wei, D., Huang, Y., Liu, Z., Shi, Y. \& Goodfellow, M. (2007). Streptomyces radiopugnans sp. nov., a radiation-resistant actinomycete isolated from radiation-polluted soil in China. Int J Syst Evol Microbiol 57, 2578-2582.

Minnikin, D. E., O’Donnell, A. G., Goodfellow, M., Alderson, G., Athalye, M., Schaal, A. \& Parlett, J. H. (1984). An integrated procedure for the extraction of bacterial isoprenoid quinones and polar lipids. J Microbiol Methods 2, 233-241.

Nachtigall, J., Kiluk, A., Helaly, S., Bull, A. T., Goodfellow, M., Asenjo, J. A., Maier, A., Wiese, J., Imhoff, J. F., Süssmuth, R. D. \& Fiedler, H.-P. (2011). Atacamycins A-C, 22-membered antitumor macrolactones produced by Streptomyces sp. C38. J Antibiot 64, 775-780.
O'Donnell, A. G., Falconer, C., Goodfellow, M., Ward, A. C. \& Williams, E. (1993). Biosystematics and diversity amongst novel carboxydotrophic actinomycetes. Antonie van Leeuwenhoek 64, 325340.

Okoro, C. K., Brown, R., Jones, A. L., Andrews, B. A., Asenjo, J. A., Goodfellow, M. \& Bull, A. T. (2009). Diversity of culturable actinomycetes in hyper-arid soils of the Atacama Desert, Chile. Antonie van Leeuwenhoek 95, 121-133.

Rateb, M. E., Houssen, W. E., Arnold, M., Abdelrahman, M. H., Deng, H., Harrison, W. T., Okoro, C. K., Asenjo, J. A., Andrews, B. A. \& other authors (2011a). Chaxamycins A-D, bioactive ansamycins from a hyper-arid desert Streptomyces sp. J Nat Prod 74, 1491-1499.

Rateb, M. E., Houssen, W. E., Harrison, W. T., Deng, H., Okoro, C. K., Asenjo, J. A., Andrews, B. A., Bull, A. T., Goodfellow, M. \& other authors (2011b). Diverse metabolic profiles of a Streptomyces strain isolated from a hyper-arid environment. J Nat Prod 74, 1965-1971.

Rong, X. \& Huang, Y. (2010). Taxonomic evaluation of the Streptomyces griseus clade using multilocus sequence analysis and DNA-DNA hybridization, with proposal to combine 29 species and three subspecies as 11 genomic species. Int J Syst Evol Microbiol 60, 696-703.

Rzhetsky, A. \& Nei, M. (1992). A simple method for testing minimum evolution trees. Mol Biol Evol 9, 945-967.

Saitou, N. \& Nei, M. (1987). The neighbor-joining method: a new method for reconstructing phylogenetic trees. Mol Biol Evol 4, 406425.

Sasser, M. (1990). Identification of bacteria by gas chromatography of cellular fatty acids. MIDI Technical Note 101. Newark, DE: MIDI Inc.

Shirling, E. B. \& Gottlieb, D. (1966). Methods for characterization of Streptomyces species. Int J Syst Bacteriol 16, 313-340.

Tamura, K., Dudley, J., Nei, M. \& Kumar, S. (2007). MEGA 4: Molecular evolutionary genetics analysis (MEGA) software version 4.0. Mol Biol Evol 24, 1596-1599.

Thompson, J. D., Higgins, D. G. \& Gibson, T. J. (1994). Clustal W: Improving the sensitivity of progressive multiple sequence alignment through sequence weighting, position-specific gap penalties and weight matrix choice. Nucleic Acids Res 22, 4673-4680.

Vickers, J. C., Williams, S. T. \& Ross, G. W. (1984). A taxonomic approach to selective isolation of streptomycetes from soil. In Biological, Biochemical and Biomedical Aspects of Actinomycetes, pp. 553-561. Edited by L. Ortiz-Ortiz, L. F. Bojalil \& V. Yakoleff. Orlando: Academic Press.

Wayne, L. G., Brenner, D. J., Colwell, R. R., Grimont, P. A. D., Kandler, O., Krichevsky, M. I., Moore, L. H., Moore, W. E. C., Murray, R. G. E. \& other authors (1987). International committee on systematic bacteriology. Report of the ad hoc committee on reconciliation of approaches to bacterial systematics. Int J Syst Bacteriol 37, 463-464.

Williams, S. T., Goodfellow, M., Alderson, G., Wellington, E. M. H., Sneath, P. H. A. \& Sackin, M. J. (1983). Numerical classification of Streptomyces and related genera. J Gen Microbiol 129, 1743-1813.

Williams, S. T., Goodfellow, M. \& Alderson, G. (1989). Genus Streptomyces Waksman and Henrici 1943, 339 AL. In Bergey's Manual of Systematic Bacteriology, vol. 4, pp. 2452-2492. Edited by S. T. Williams, M. E. Sharpe \& J. G. Holt. Baltimore: Williams \& Wilkins. 